\title{
The Stress-Reducing Effects of Forest Healing Activities in Maladjusted Military Force Members
}

\author{
Jihye $\mathrm{Kim}^{1}$, Changseob $\mathrm{Sin}^{2}$, Jihye $\mathrm{Kim}^{3 *}$, Dohyeong $\mathrm{Kim}^{3}$, Yunsu Kim${ }^{3}$, and Hyunchae $\mathrm{Lee}^{3}$ \\ ${ }^{1}$ Doctoral student, Graduate Department of Forest Therapy, Chungbuk National University, Cheongju 28864, Korea \\ ${ }^{2}$ Professor, Department of Forest Science, Chungbuk National University, Cheongju 28864, Korea \\ ${ }^{3}$ Researcher, leumforest Inc., Seoul 05315, Korea
}

\section{ABSTRACT}

Background and objective: In the Republic of Korea, military service is mandatory. Some of new recruits have the stress from the special environment, which could cause psychological maladjustment. The military forces have operated education programs such as green camp and healing camp. The study was conducted to investigate changes in psychological and physiological stress by conducting forest healing activities along with plant scent treatment for soldiers participating in a green camp.

Methods: A total of 52 soldiers were participated including maladjustment soldiers and those recommended by their military units to protect the unfit soldiers who participated in forest healing activities in the green camp. The programs that were certified by the Korea Forest Service between 2014 and 2019, and were applied for stress reduction and relaxation training were classified into stress-coping programs and forest experience programs. Post-hoc surveys and cortisol measurements were carried out.

Results: Green camp soldiers experience and differences in the level of stress responses were found to be very statistically significant between the treatment and control groups. The techniques for coping with stress were not significantly different in the control group, and the treatment group showed statistically significant results. In addition, the results of analyzing changes in the concentration of cortisol and measuring physiological stress were very statistically significant in forest healing activities at 4 p.m.

Conclusion: Once green camp soldiers face stressful situations, forest healing programs using forest plant scents for green camp soldiers can have positive responses and forest healing activities can reduce psychological and physiological stress responses, improving maladjustment behaviors caused by stress and positively affecting the reduction of cortisol.

Keywords: cortisol, green camp, mental health, therapy

\section{Introduction}

Article 39(1) of the Constitution of the Republic of Korea states that all citizens shall have the duty of national defense under the conditions as prescribed by Act. For the duty of national defense prescribed by the Constitution, mandatory military service is set by Article 3 of the Military Service Act in the Republic of Korea. According to the status of active duty servicemen in 2015 released by the Military Manpower Administration, about 110,000 young males aged 19 years or older are drafted annually. As young males who lead a free social life have to adapt to military life, the stress that privates and first class privates experience increases in the special environment of military service where individuals cannot freely express their will or act at their own discretion (Jung, 2007), and the stress in military life causes psychological maladjustment (Jung and Lee, 2013). New recruits have to accept

This Research was supported by the Green fund 2019 and Captain Jung Bae Kim of 6th corps Green Camp.

Received: April 6, 2020, Revised: April 16, 2020, Accepted: May 8, 2020

First author: Jihye Kim, ieumforest@gmail.com, (10) https://orcid.org/0000-0002-2004-1665

*Corresponding author: Jihye Kim, ieumforest@ieumforest.or.kr, (10) https://orcid.org/0000-0002-3860-311X 
and adapt to the new environment of military service like restrictions and top-down culture and hierarchy. Of course, individuals show different responses to stress even under the same situation, and stress itself does not have uniform symptoms, which makes it difficult to properly cope with stress (Lazarus and Folkman, 1984). However, the burden and stress that soldiers experience inevitably increase in any situation. According to the report published by the Korea Institute of Behavioral Sciences in 1986, the degree and level of socialization that individuals learn differ, and the stress caused by this and anxiety over the future makes it more difficult to soldiers to adapt to military life. Moreover, those who experience military adjustment disorders perceive surroundings as a very unstable and dangerous situation similar to the level of those with anxiety disorders and experience excessive stress (You, 2006). Since the stress accumulated for a long time cause maladjustment problems in the system of stress (Chrousos and Kino, 2007), various measures to properly reduce the stress level of soldiers including new recruits must be developed and implemented. The military forces of the Republic of Korea have operated education programs such as green camp and healing camp, but the environment itself still has other intrinsic factors that can cause conflicts. In the atmosphere, it is difficult to expect proper healing. Even those who received professional treatment from military psychiatrists often show no improvement in their maladjustment behaviors and some of those who are found to be unfit for military service by the military service screening unit are kicked out of their units. Managing help and care soldiers separately can be a burden to military officers who are already busy with controlling their units. This system for maladjustment soldiers in the military forces is designed not to heal individuals, but to prevent any related accidents in advance by identifying unfit soldiers.

Currently, 20 corps- or division-level green camps are operated in the army in Korea, and 16 camps (80\%) operate 2-week programs required by the accident prevention and management code (partially amended on April 1, 2016); two camps (10\%), 3-week programs; and two camps (10\%), 4-week programs. They operate various programs to achieve the objectives of green camps - mental and psychological healing and improved adjustment in military service - but in reality it is difficult to expect healing effects due to the short periods of camps and programs.

For this reason, it is urgently needed to develop healing programs suitable for maladjustment soldiers.

Military units are mostly surrounded by forests due to their geographical and environmental factors and can utilize forests to restore stress (Park, 2010), but for soldiers, as young adults who are accustomed to modern civilization, the forests seen from their military units are recognized not as a healing space where they can secure their own space and seek inner peace and psychological stability but as a space for training their body (Kim, 2019). In this light, forests around military units can be utilized to reduce the stress that soldiers experience in their military life, increase positive emotions and emotional stability, and thus to ensure they can effectively cope with the stress.

Selye (1979) defined stress as the non-specific response of the body created in the process of physiological adaptation to protect the body from external stimuli. It is very difficult to measure and interpret stress due to its abstract and subjective characteristics. For this reason, a questionnaire survey is used as a tool to quantitatively measure stress with a scale for assessing individuals' perceived psychological state (Dunn, 1997), and it is possible to obtain relatively objective and accurate data using the method. However, individuals' subjectivity can be reflected too much, which reduces reliability and validity, and a significant amount of expertise is required to interpret and analyze its results (Andre and Wickens, 1995). To remedy these disadvantages, cortisol in serum, saliva or urine is measured as a reliable biomarker to accurately measure biochemical stress responses (Kim et al., 2004).

Cortisol is a hormone produced mainly due to stress and thus is called stress hormone. Cortisol is a steroid hormone produced by the adrenal glands which sit on top of each kidney and are cone-shaped and smaller than an adult's thumb. When a stress stimulus occurs, neurons in the paraventricular nucleus (PVN) in the hypothalamus produce corticotropin-releasing hormone $(\mathrm{CRH})$ and again stimulate the pituitary gland and produce adrenocorticotropic hormone $(\mathrm{ACTH})$ which is transferred to adrenal glands through blood and induces the production of glucocorticoids (GC) and cortisol. The level of cortisol rises and falls 
throughout the daily cycle. It increases early in the morning, reaching the highest at around 8 a.m. and continues to sharply decrease until 11 a.m. After that, the level of cortisol gradually decreases and starts to increase again between midnight and 2 a.m. For this reason, it is recommended to measure cortisol 4-5 times a day according to its daily rhythm (Schmidt-Reinwald et al., 1999).

When measuring cortisol in blood, stress can be temporarily induced and differences in responses among individuals can be amplified (Sreebny, 2000). In addition, blood samples can be collected only by medical professionals. Using the method of measuring cortisol in saliva, however, salivary samples can be easily collected from the salivary gland under the tongue and only $2-3 \mathrm{ml}$ needs to be collected. For this reason, the method can be easily applied on-site and samples can be collected multiple times according to the daily rhythm of cortisol, which increases validity (Ann et al., 2008).

A forest is a place where stress can be effectively dealt with simply by visiting or staying in forests or doing exercises in forests (Mass et al., 2009). Phytoncide emitted from trees in forests has been reported to have positive physical and psychological effects. Simply by inhaling phytoncide, the level of daily stress and the level of stress hormones in blood can be reduced (Nam and Uhm, 2008). Forest healing activities are more effective in reducing and recovering from physical and mental stress, and can also physiologically reduce a stress index, increasing resistance against stress (Park et al., 2014). In addition, stress responses can be controlled by changing situations or changing individuals' negative emotions or managing physical responses (Kogan and Betrus, 1984), and forest experience was reported to have a positive influence on both help and general soldiers' feelings and military stress (You and Shin, 2017). Since managing stress in this way acts as a direct factor in their adjustment in military life (Joe, 2003), it is necessary to develop measures to manage stress for maladjustment soldiers.

Against this backdrop, this study aimed to examine whether forest healing activities utilizing the scent of plants in a green camp that are provided for maladjustment soldiers can reduce in forests the level of stress that they experience. To do so, this study measured changes in the level of stress responses, the score of the psychological scale used to compare stress-coping techniques and the level of salivary cortisol when green camp soldiers experienced a forest healing program. In addition, the level of stress that both maladjustment and exemplary soldiers in the green camp was examined together.

\section{Research Methods}

\section{Objects}

To examine the effects of forest healing programs on the stress level of soldiers who participate in green camps, soldiers of $\mathrm{S}$ corps located in Gyeonggi-do were divided into the treatment group of 26 maladjustment soldiers who participated in the green camp operated by the corps and the control group of 26 exemplary soldiers. The treatment group participated in a total of two sessions under the forest healing program designed in this study, while the control group did not participate in the program. The soldiers were recommended by their military units and agreed to voluntarily participate in this study after being informed of the purposes and methods of this study. This study was conducted from January 14 to March 25, 2019, and according to the curriculum of the green camp that is operated for 2 weeks for each class, a total of six sessions were operated for three classes, two sessions for each class. The forest healing program was operated by one forest education expert and one assistant. Those who participated in the green camp were unfit soldiers called 'help soldiers' and they were classified as a high-risk solider who is highly likely to cause accidents within military units, needs to be immediately separated from others and needs an immediate treatment as they are unfit for military service. They are classified according to the criteria for classifying supports for military personnel (Article 232-2 of the Unit Management Directive; Ministry of National Defense Directive No. 2273, 2019). Exemplary soldiers, as members of the same platoon of the maladjustment soldiers who participate in green camps, are assigned to protect the maladjustment soldiers. The average age of the treatment and control groups was $22(21.80 \pm 0.56)$ years and $23(22.42 \pm 1.27)$ 
years respectively. In terms of their rank, there were two privates $(7.69 \%)$, one first class private $(57.69 \%)$, eight corporals $(30.77 \%)$ and one sergeant $(3.85 \%)$ in the treatment group, while there were one private (3.85\%), 12 first class privates $(46.15 \%)$, nine corporals $(46.15 \%)$ and four sergeants $(15.38 \%)$.

\section{Methods}

The purposes, goals, content and methods of the forest healing program suitable for green camp soldiers were set based on the stress-coping program developed for 52 maladjustment soldiers and exemplary soldiers and the programs certified by the Korea Forest Service in order to reduce the stress that maladjustment soldiers experience and improve their stress response techniques. The program was also designed based on earlier studies on forestry, horticultural therapy, alternative medicine, counseling psychology, educational psychology, etc. related to green camp soldiers and other studies related to stress relaxation, communication and positive psychological changes in interpersonal relationships (Jang et al., 2010). In particular, the method suggested by Song and Lee (2004) was revised to reduce stress from new activities by repeating in each session activities that were designed considering individuals' characteristics and forests' seasonal elements to meet the objectives of activities.
In addition, the programs that were certified by the Korea Forest Service between 2014 and 2019 and were applied for stress reduction and relaxation training were classified into stress-coping programs and forest experience programs. The program used in this study was designed to perform two sessions a month and its detailed content is as follows. The non-equivalent groups were compared through pre- and post-tests, and the assessment of the forest healing effects was performed a total of 2 times before and after operating the forest healing program using a questionnaire survey and a cortisol test (Table. 1).

\section{Stress reduction program design}

Based on the results of Ulrich (1983) that seeing or visiting the natural environment after receiving stress stimuli is good for psychological stability and recovery, the program used in this study was comprised of activities of meditating and feeling forest environments. It was also reported that the active components in the scent of plants are related to biologically active substances (Fabricant and Farnsworth, 2001) and that diterpenoids separated from the woods and leaves of Tetraclinis articulata showed similar immunoregulatory effects (Barrero et al., 2003). The body after forest bathing was also reported to show stable brainwaves, blood pressure and pulse relaxation and reduced stress, which resulted in physiological changes and an increase

Table 1. Examples of forest healing programs for green camp participating soldiers

\begin{tabular}{|c|c|c|c|}
\hline \multirow{2}{*}{ Time } & \multicolumn{2}{|c|}{ Activity contents } & \multirow{2}{*}{ Support objective } \\
\hline & The first session & The second session & \\
\hline $\begin{array}{l}\text { Introduction } \\
\text { (50 min) }\end{array}$ & $\begin{array}{l}\text { - Greetings, program introduction } \\
\text { - Opening body and mind } \\
\text { - Pre-survey }\end{array}$ & $\begin{array}{l}\text { - Greetings, program introduction } \\
\text { - Opening body and mind }\end{array}$ & $\begin{array}{l}\text { - Affinity formation } \\
\text { - Pre-personal tendencies test }\end{array}$ \\
\hline $\begin{array}{l}\text { Implementation } \\
\text { (110 } \mathrm{min})\end{array}$ & $\begin{array}{l}\text { - Forest tracking } \\
\text { - Finding scent } \\
\text { - Describing essential oils } \\
\text { - Learning about scents and } \\
\text { personal taste } \\
\text { - Plant aroma therapy } \\
\text { - Making perfumes }\end{array}$ & $\begin{array}{l}\text { - Forest tracking } \\
\text { - Finding scent } \\
\text { - Learning about scents and personal taste } \\
\text { - Plant aroma therapy } \\
\text { - Making own massage oils for hand and } \\
\text { foot massage }\end{array}$ & $\begin{array}{l}\text { - Stabilizing mind and body } \\
\text { through forest factor } \\
\text { - Understanding essential oil types } \\
\text { - Mental and physical healing } \\
\text { through the scents of plants }\end{array}$ \\
\hline $\begin{array}{l}\text { Wrap-up } \\
(20 \mathrm{~min})\end{array}$ & $\begin{array}{l}\text { - Forest meditation } \\
\text { - Post-management guide }\end{array}$ & $\begin{array}{l}\text { - Forest meditation } \\
\text { - Post-management guide } \\
\text { - Post-survey }\end{array}$ & $\begin{array}{l}\text { - Positive self-forming } \\
\text { - Learning how to be mentally and } \\
\text { physically stable (self-stress } \\
\text { management) }\end{array}$ \\
\hline
\end{tabular}


in psychological stability (Lee and Lee, 2012). Another study reported that utilizing a natural oil from plants is a holistic treatment that can heal psychological states such as stress depression and anxiety from mental, physical and emotional perspectives, and that physical treatment and inhaling aroma were effective in reducing and preventing stress (Jun et al., 2007). Based on the results of these studies, the forest healing program was designed to utilize the scent of plants according to individuals' characteristics.

\section{Tools}

(1) Stress Response Inventory-Modified Form (SRI-MF)

The Stress Response Inventory (SRI) was developed by Koh et al. (2000) in 2000 and Choi et al. (2006) modified it into a questionnaire form called the Stress Response Inventory-Modified Form (SRI-MF) in order to increase its clinical usability. The SRI-MF is comprised of a total of 22 questions and they are divided into three factors including physical, depressive and anger symptoms. Each question is assessed using a scale of 0-4 points, and the higher the total score, the higher the level of stress. It is interpreted that those with a total score ranging between 0 and 31 points can control stress properly and that those with a total score ranging between 32 and 49 points show stress symptoms but can manage themselves. Those with a total score of 50 points or higher are classified into a high-risk group and need accurate diagnosis and counseling from medical professionals and continuous management. The Cronbach's $\alpha$ of the SRI-MF is .67-.71, and the value in this study was .774.

\section{(2) Stress-coping techniques}

Stress-coping techniques mean the methods of successfully coping with stress in harsh situations and when people have various stress-coping mechanisms, stress sources do not last long or lead to negative results (Kostelnik et al., 2015). Therefore, coping is recognized as a behavioral or cognitive effort to handle conflicts between environment and internal demands (Lazarus and Folkman, 1984). If individuals can have techniques of effectively coping with stressful situations, the situations will no longer be perceived as a threat (Yi, 1999).
The level of stress that individuals perceive as a threat affects the ability of coping with stress, and an excessive level of threatening stress affects their cognitive functions and information processing ability, which disturbs problem-focused coping (Lazarus and Folkman, 1984). For this reason, individuals' stress-coping techniques can affect the psychological and behavioral state of maladjustment soldiers.

The revised stress-coping scale of Kim (1987) was modified again by Sim (1995) to increase its clinical usability. The questionnaire is comprised of a total of 20 questions, nine questions on problem-focused coping and 11 questions about emotion-focused coping. Each question is assessed using a scale of 0-4 points, and the higher the total score, the better stress is coped with. The Cronbach's $\alpha$ of stresscoping techniques was .873 .

\section{(3) Salivary cortisol measurement}

To measure the level of stress using a biochemical test, salivary cortisol samples were collected before and after operating the forest healing program at $4 \mathrm{p} . \mathrm{m}$. on the day and at 7 a.m., 30 minutes after getting up on the next day (6:30 a.m.). In a salivary-test container with the name of soldiers and the time of collection written on it, 2-3 ml of saliva was collected, and individual containers were tightly sealed with a cover, were placed in a sealed PEP pack and were frozen at $-20{ }^{\circ} \mathrm{C}$. The same process was repeated four times. Cortisol ELISA (High Sensitivity Salivary Cortisol Enzyme Immunoassay Kit, 2015, Salimetrics LLC, USA) was used to measure salivary cortisol following the instructions provided by Salimetrics. Jin Myung Biocare (Seongsan-ro 321, Seodaemun-gu, Seoul, South Korea) was commissioned to test the samples using a tester (Model 680 Microplate reader, 2015, Bio-Rad, US) to unfreeze and centrifuge the samples to separate their supernatant liquid.

The normal range of samples suggested by ELISA was 3-10 ng/l 30 minutes after getting up and 1.0-2.5 ng/l at 4 p.m. Choi (2008) reported that sharp fluctuations in the level of cortisol fluctuates sharply within the normal range of adults mean good stress recovery. 
Table 2. Comparison of stress response levels of soldiers participating in green camp before and after forest healing activities

\begin{tabular}{|c|c|c|c|c|c|c|c|}
\hline Group & Time & $\mathrm{n}$ & M & SD & $\mathrm{t}$ & df & $p$ \\
\hline \multirow{2}{*}{ Treatment } & Before & 26 & 62.0 & 14.07 & \multirow{2}{*}{7.250} & \multirow{2}{*}{25} & \multirow{2}{*}{$<.001^{* * *}$} \\
\hline & After & 26 & 21.0 & 23.14 & & & \\
\hline \multirow{2}{*}{ Control } & Before & 26 & 52.96 & 23.76 & \multirow{2}{*}{6.190} & \multirow{2}{*}{25} & \multirow{2}{*}{$<.001^{* * *}$} \\
\hline & After & 26 & 18.81 & 16.35 & & & \\
\hline
\end{tabular}

${ }^{* * *} p<.001$ before and after the program by paired t-test.

\section{Data analysis methods}

The Stress Response Inventory - Modified Form (SRI-MF), stress-coping techniques and cortisol test were performed on green camp soldiers before and after operating the program one time respectively. The collected data were analyzed using IBM SPSS software (version 23 for Windows; IBM corp., Armonk, NY, USA), and average differences in the level of stress responses and stress coping between groups were analyzed through a paired t-test. The level of cortisol was analyzed based on the patterns of fluctuations in the produced cortisol level, and the homogeneity of groups was analyzed through an independent t-test. The reliability of the stress response inventory and stress-coping techniques was analyzed by calculating their Cronbach' $\alpha$.

\section{Results and Discussion}

The lower the total score of the stress response inventory, the more statistically significant the results. The average score of the control group was reduced and showed statistically significant differences $(\mathrm{t}=7.25, \mathrm{df}=25$, $p<.001)$. The treatment group also showed a decrease in its average score, and the differences were found to be very statistically significant $(\mathrm{t}=6.190, \mathrm{df}=25, p<.001)$.

As such, the molecules of the plant scents applied to individual soldiers stimulate the olfactory nerves of the olfactory bulb and the information is transferred to the olfactory brain, having a healing effect on the autonomic nervous system (Kim, 2011). This reduces the psychological and physical stress that soldiers experience, acting as a positive factor on stress reduction and forest healing activities performed in forests within military units seem to change stressful situations or negative emotions or to control phys- ical responses (Kogan and Betrus, 1984). Likewise, forest healing activities seem to have a positive impact on reducing the stress that green camp soldiers experience (Table 2).

The results of testing stress-coping techniques showed a slight increase in the average score of the control group, but the differences were not statistically significant $(\mathrm{t}=-1.656$, $\mathrm{df}=25, p=.110)$. Since those in the control group did not participate in forest healing activities, their stress-coping techniques did not seem to be affected. Whereas, the treatment group showed an increase in the average score $(\mathrm{t}=-3.430, \mathrm{df}=25, p=.002)$, showing statistically significant differences.

As such, with stress-coping techniques, stress can be effectively coped with through forest healing activities (Mass et al., 2009), and improvements in stress-coping techniques through the activities can strengthen individuals' ability to overcome frustrations that they experience from interpersonal relationships, address problems and accept challenges, which makes people overcome stress better (Bai, 2006). These results indicate that forest healing activities have a positive impact on maladjustment soldiers' stresscoping techniques (Table 3).

Based on changes in the level of salivary cortisol, patterns in fluctuations in cortisol were analyzed using the method of analyzing the level of cortisol suggested by Choi (2008), and the method was revised considering changes in the cortisol concentration according to its daily cycle in this study.

Sharp fluctuating patterns within the normal range mean good stress recovery. The results of this study showed no statistically significant difference in the level measured at 7 a.m. $(\mathrm{t}=-1.846, \mathrm{df}=25, p=.075)$. Whereas, the level measured at 4 p.m. right after forest healing activities showed statistically significant differences. The average cortisol 
Table 3. Comparison of stress response techniques of soldiers participating in green camp before and after forest healing activities

\begin{tabular}{cccccccc}
\hline Group & Time & $\mathrm{n}$ & $\mathrm{M}$ & $\mathrm{SD}$ & $\mathrm{t}$ & $\mathrm{df}$ & $p$ \\
\hline \multirow{2}{*}{ Treatment } & Before & 26 & 1.54 & 1.07 & -3.430 & 25 & $.002^{* *}$ \\
& After & 26 & 2.35 & 1.02 & & & \multirow{2}{*}{$.110^{\text {NS }}$} \\
Control & Before & 26 & 2.15 & 0.92 & -1.656 & 25 & \\
& After & 26 & 2.62 & 1.02 & & & \\
\hline
\end{tabular}

${ }^{\mathrm{NS}}$ Non-significant, ${ }^{* *} p<.01$ by paired t-test.

Table 4. Comparison of cortisol secretion of soldiers participating in green camp before and after forest healing activities

\begin{tabular}{cccccccc}
\hline Group & Time & $\mathrm{n}$ & $\mathrm{M}$ & $\mathrm{SD}$ & $\mathrm{t}$ & $\mathrm{df}$ & $p$ \\
\hline \multirow{2}{*}{ Treatment } & Before & 26 & 5.44 & 1.93 & & 25 & $<.001^{* * *}$ \\
& After & 26 & 3.49 & 0.99 & 4.877 & & 25 \\
\multirow{2}{*}{ Control } & Before & 26 & 4.85 & 1.81 & \multirow{2}{*}{0} & 2.648 & 25 \\
& After & 26 & 3.57 & 1.25 & & \\
\hline
\end{tabular}

${ }^{*} p<.05,{ }^{* * *} p<.001$ by paired t-test.

level of the control group before and after forest healing activities was $4.85 \mathrm{ng} / \mathrm{ml}$ and $3.57 \mathrm{ng} / \mathrm{ml}$ respectively, showing a statistically significant difference $(\mathrm{t}=2.648$, $\mathrm{df}=25, p=.014)$. The average cortisol level of the treatment group before and after forest healing activities was $5.44 \mathrm{ng} / \mathrm{ml}$ and $3.49 \mathrm{ng} / \mathrm{ml}$ respectively, and the difference was very statistically significant $(\mathrm{t}=4.877, \mathrm{df}=25, p<.001)$. The depth of the fluctuations of the treatment group $(1.95 \mathrm{ng} / \mathrm{l})$ was higher than that of the control group $(1.28 \mathrm{ng} / \mathrm{ml})$, indicating that the treatment group recovered from stress better than the control group. It was also reported that inhaling and experiencing the scent of plants reduced stress-related hormones including ACTH and cortisol, and were effective in reducing and preventing stress at an early stage (Kim, 2007). These results indicate that the forest healing program positively affects the reduction of stress that green camp soldiers experience (Table 4).

As such, forest healing activities affect the immunoregulation of the endocrine system and reduce stress, improving physiological changes and psychological stability (Lee and Lee, 2012). This indicates that forest healing activities as a phytotherapy are more effective in reducing and recovering from physical and mental stress (Park et al., 2014), and that forest healing activities utilizing the scent of forests have a positive impact on stress reduction.

\section{Conclusion}

The purposes of this study were to examine the stress that maladjustment soldiers experience through literature review, and to operate a program that utilized the scent of plants of which effectiveness was proved, focusing on individuals' stress reduction and management. In particular, this study focused on self-management and stress reduction by ensuring they can reduce negative stress and utilize positive stress fully. A total of 52 soldiers of S corps located in Gyeonggi-do, and they included maladjustment soldiers who participated in the green camp operated by the corps, and exemplary soldiers who were recommended by their military units to protect the maladjustment soldiers. The subjects of this study were selected among the soldiers recommended by their military units agreed to voluntarily participate in this study after being informed of the purposes and methods of this study. A questionnaire survey and cortisol test were conducted before and after the program. This study was conducted from January 14 to March 25, 2019, and a total of six sessions for three classes, two sessions for each class, were operated under the forest healing program. The Stress Response Inventory - Modified Form (SRI-MF) and stress-coping techniques were used as a tool to assess stress, and the level of salivary cortisol was meas- 
ured to examine the effects of the program on their stress. The results were as follows. Forest healing activities utilizing the scent of plants were provided for the soldiers to examine their effects on the reduction of stress that green camp soldiers experience, and no statistically significant difference was observed between the treatment and control groups, indicating that the treatment and control groups were homogeneous. The forest healing program was provided to examine its effects on the reduction of stress that green camp soldiers experience, and differences in the level of stress responses between the treatment and control groups were found to be very statistically significant $(p<.001)$. The results of testing stress-coping techniques showed no statistically significant difference in the control group ( $p<.110$ ), but the experiment group showed statistically significant differences $(p<.01)$. In addition, changes in the concentration of cortisol, a physiological stress index, were analyzed, and very statistically significant results were observed after performing forest healing activities $(p<.001)$. These results indicate that stress can be changed into a stable state and that forest healing activities utilizing the scent of plants in forests for green camp soldiers were effective in helping them positively handle stressful situations, reducing their psychological and physiological stress responses, improving their maladjustment behaviors caused by stress and positively affecting the reduction of cortisol. For this reason, forest healing activities utilizing the scent of plants are expected to improve soldiers' psychological and physiological stress management ability, to reduce negative stress and thus to help them return to healthy military life, and it will be necessary to continuously conduct studies on this in detail.

\section{References}

Andre, A.D. and C.D. Wickens. 1995. When uses want what's not best for them. Ergon. Des. 3(4):10-14. https://doi.org/10.1177/106480469500300403

Ann, G.J., J.S. Jeong, Y.G. Kim, and H.S. Jeong. 2008. Physiological markers in anxiety and depression. J Korean Biol. Nurs. Sci. 10(2):184-193.

Bai, J.S. 2006. The effect of stress self esteem and social support on depression-with the youth of the rural and fishing areas. Master's thesis, Chonnam National University, Gwangju, Korea.

Barrero, A.F., J.F. Quilez del Moral, R. Lucas, M. Paya, M. Akssira, S. Akaad, and F. Mellouki. 2003. Diterpenoids from tetraclinis articulata that inhibit various human leukocyte functions. J. Nat. Prod. 66(6):844-850. https://doi.org/10.1021/np0204949

Choi, J.Y. 2008. Cortisol level of day care children: Relations with day care characteristics, SES, mothers' parenting behaviors, and children's social competence. Doctoral dissertation, Yonsei University, Seoul, Korea.

Choi, S.M., T.Y. Kang, and J.M. Woo. 2006. Development and validation of a modified form of the stress response inventory for workers. J. Korean Neuropsychiatr. Assoc. 45(6):541-553.

Chrousos, G.P. and T. Kino. 2007. Glucocorticoid action networks and complex psychiatric and/or somatic disorders. Stress 10(2):213-219.

Dunn, D.S. 1997. Stress measurement: Interdisciplinary and state of the art [Review of the book Measuring Stress: A guide for health and social scientist by S. Cohen, R.C. Kessler, L.U. Gordon (Eds.)] PsycCRITIQUES 42(1):56-57.

Fabricant, D.S. and N.R. Farnsworth. 2001. The value of plants used in traditional medicine for drug discovery. Environ. Health Perspect. 109(Suppl. 1):69-75. https://d oi.org/10.1289/ehp.01109s169

Jang, E.J., G.W. Han, J.W. Hong, S.E. Yoon, and C.H. Pak. 2010. Meta-analysis of research papers on horticultural therapy program effect. Korean J. Hortic. Sci. Technol. 28(4):701-707.

Joe, S.Y. 2003. Relations of health promoting behaviors, mental health, and military life adjustments of soldiers. J. Korean Acad. Psych. Mental Health Nurs. 12(2):164-171.

Jun, Y.S., J.S. Kim, and C.M. Park. 2007. The influence of beauty education program the disabled women: For the hearing and mental disabled women. J. Korean Soc. Cosmetol. 13(3):989-1000.

Jung, H.J. 2007. The stress coping style and military life adjustment of soldiers. Master's thesis, Kyungpook National University, Daegu, Korea.

Jung, S.G. and E.H. Lee. 2013, August. Military service stress and psychological maladjustment: The mediating 
role of child modes. Proceedings of Annual Conference of the Korean Psychological Association(p. 389).

Kim, D.S., Y.S. Jeong, and S.W. Park. 2004. Relationship between the stress hormone, salivary cortisol level and stress score by self-report measurement. Korean J. Health Psychol. 9(3):633-645.

Kim. J.B. 2019. Education programs research and development corps level green camp: Focused on ' $U$ ' corps. Master's thesis, Daejin University, Pocheon, Korea.

Kim, J.H. 1987. Relations of perceived stress, cognitive set, and coping behaviors to depression. Doctoral dissertation, Seoul National Univ, Seoul, Korea.

Kim, J.S. 2007. Effects of the aromatherapy on stress related hormones. Doctoral dissertation, Keimyung University, Daegu, Korea.

Kim, Y.N. 2011. The study on effect of anti-stress managed by aroma essence oil therapy through oldfactory. Master's thesis, Kyounggi University, Seoul, Korea.

Kogan, N.H. and A.P. Betrus. 1984. Self-management: A nursing mode of therapeutic influence. ANS Adv. Nurs. Sci. 6(4):55-73.

Koh, K.B., J.K. Park, and C.H. Kim. 2000. Development of the stress response inventory. J. Korean Neuropsychiatr. Assoc. 39(4):707-719.

Kostelnik, M.J., A. Soderman, A. Whiren, M.L. Rupiper, and K. Gregory. 2015. Guiding children's social development and learning(8th ed.). Boston, MA: Cengage Learning US.

Lazarus, R. and S. Folkman. 1984. Stress, appraisal, and coping. New York, NY: Springer Publishing Co. Springer Publishing Co.

Lee, B.K. and H.H. Lee. 2012. A study on the effects of human physiology after forest phytoncide therapy. J. Naturopathy. 1(1):14-20.

Maas, C., U. Schraml, C. Hornberg, and T. Cla $\beta$ en. 2009, April. Frische waldluft fur die mitarbeiter ! waldtage als stress reduzierende handlungsstrategie in der betrieblichen gesundheitsforderung [Fresh forest air for the employees! Forest days as a stress-reducing action strategy in corporate health requirements]. In: Corporate health promotion in 2009 for Swiss Federal Institute for forest, Snow, and Landscape Research WSL on 'Health and relaxation in the forest and landscape'(p. 53). Birmensdorf, Swiss.
Ministry of National Defense Directive, No. 2273. 2019. Section 232-2.

Nam, E.S. and D.C. Uhm. 2008. Effect of phytoncide inhalation on serum cortisol level and life stress of college students. J. Korean Acad. Adult Nurs. 20(5):697-706.

Park, B.J. 2010. Experimental approach of therapeutic effect of forest recreation activities: Focused on viewing and walking in forest environments. Doctoral dissertation, Chungnam National University, Daejeon, Korea.

Park, H.S., C.S. Shin, P.S. Yeoun, and J.Y. Kim. 2014. A comparative study on the stress recovery effect of forest therapy. J. Korean Inst. For. Recreat. 18(1):13-24. https://doi.org/10.34272/forest.2014.18.1.002

Schmidt-Reinwald, A., J.C. Prussner, D.H. Hellhammer, I. Federenko, N. Rohleder, T.H. Schürmeyer, and C. Kirschbaum. 1999. The cortisol response to awakening in relation to different challenge tests and a 12-hour cortisol rhythm. Life Sci. 64(18):1653-1660. https://doi.org/10.1016/S0024-3205(99)00103-4

Selye, H. 1979. The stress of life. New York, NY: McGrawHill Education.

Sim, S.J. 1995. The effect on stress level by assertiveness and the way of stress coping. The Catholic University of Korea, Bucheon, Korea.

Song, J.A. and Y.H. Lee. 2004. Study of the relationship between children's daily stress and antisocial behavior. J. Human Life Sci. [Sungkyunkwan University] 7:189-206.

Sreebny, L.M. 2000. Saliva in health and disease: An appraisal and update. Int. Dent. J. 50(3):140-161. https://doi.org/10.1111/j.1875-595X.2000.tb00554.x

Ulrich, R.S. 1983. Aesthetic and affective response to natural environment. In: I. Altman \& J.F. Wohlwill (Eds), Behavior and the natural environment. Human behavior and environment: Advances in theory and research (6th ed., pp. 85-126). Boston, MA: Springer.

Yi, I.H.1999. Effects of stress and coping on body perception. Korean J. Health Psychol. 4(1):80-93.

You, B.G. 2006. Comparison analysis of psychopathology between soldiers admitted for adjustment. Master's thesis, Ajou University, Suwon, Korea.

You, J.H. and W.S. Shin. 2017. The influence of green camp on soldiers' mood states and military stress. J. Korean Inst. For. Recreat. 21(4):1-8. https://doi.org/10.3 4272/forest.2017.21.4.001 